\title{
Towards a sustainable manufacturing system design: A multi-objective optimization model
}

\author{
Reda Nujoom, Qian Wang and Ahmed Mohammed \\ School of Engineering, University of Portsmouth \\ Portsmouth, UK \\ Reda.Nujoom@port.ac.uk
}

\begin{abstract}
Developments of sustainable manufacturing systems are considered as one of effective solutions to minimize the environmental impact. Design of a sustainable manufacturing system can be partially achieved through the implementation of lean methods to reduce manufacturing wastes and operational costs, and increase the system efficiency and productivity. However, the lean approach does not include environmental wastes in such as energy consumption and $\mathrm{CO}_{2}$ emissions when designing a lean manufacturing system. This paper addresses these issues by evaluating a sustainable manufacturing system design considering energy consumption, $\mathrm{CO}_{2}$ emissions and the total cost using the multi-objective approach. To this aim, a multi-objective mathematical model was developed under economic and ecological constraints in terms of minimization of the total cost, energy consumption and $\mathrm{CO}_{2}$ emissions associated with the number of machines involved in each process in conjunction with a quantity of material flow for processing these products in a manufacturing system. A real case study was used for examining the validation and applicability of the developed sustainable manufacturing system model.
\end{abstract}

Keywords-Sustainable manufacturing systems; Energy consumption; $\mathrm{CO}_{2}$; Lean manufacturing; Environmental constraints; Multi-objectives.

\section{INTRODUCTION}

To design a sustainable manufacturing system, manufacturing system designers need not merely to apply traditional methods of improving system efficiency and productivity but also to examine the environmental impact on the developed system [1]. The traditional manufacturing system design is involved in determination and analysis of such as system capacities, material flow, material-handling methods, production methods, system flexibilities, operations and shopfloor layouts. However, there is an environmental aspect that needs also to be addressed as a new challenge for manufacturing systems designers to seek an effective approach incorporating environmental parameters or constraints [2]. In the past decade, the concept of sustainable manufacturing systems has been used for promoting a balance between the environmental impact and the economic performance for production [3]. The term of manufacturing sustainability may be defined as the creation of manufactured products by reducing negative environmental impacts on usage of energy consumption or natural resources [4]. This concept ought to be implemented as a separate objective at the early design stage, together with other classical objectives in maximizing system productivity or system efficiency and or minimizing costs for production, which form a multi-objective optimization (MOO) problem [3].

Development of a sustainable manufacturing system design may be partially achieved by applying lean methods as a trend in modern manufacturing enterprises for improving system efficiency and productivity without additional investments. Lean manufacturing can be defined as "a systematic approach to eliminate non-value added wastes in various forms and it enables continuous improvement" [4]. These wastes are waiting for parts to arrive, overproduction, unnecessary movement of materials, unnecessary inventory, excess motion, the waste in processing and the waste of rework [5]. Nevertheless, traditional lean manufacturing method does not consider environmental wastes of such as energy and $\mathrm{CO}_{2}$ emissions which also need to be addressed as these wastes add no values on manufactured products $[4,5]$. Consequently, it is important to develop the lean manufacturing system design towards the sustainability incorporating the economic and ecological constraints. This is because industrial factories consume energy and subsequently produce $\mathrm{CO}_{2}$ emissions, which also need to be considered in the manufacturing system design.

There are a few studies in considering environmental aspects related to design of manufacturing systems or sustainable manufacturing systems. Heilala et al. [6] argued that manufacturing system designers need to not merely rely on traditional methods in improvements of system efficiency and productivity but also incorporate environmental considerations into design and operation of the developed manufacturing processes or systems. Wang et al. [7] proposed a method to be known as process integration (PI) method that was used for evaluating $\mathrm{CO}_{2}$ emissions for a steel industry. Branham et al. [8] presented the quantitative thermodynamic analysis for measuring the amount of energy in various categories used by manufacturing system. Guillen-Gosalbez and Grossmann [9] developed a bi-criterion stochastic mixed-integer nonlinear program (MINLP) used for optimising a sustainable chemical supply chains design through the minimization of the environmental impact.

The multi-objective optimization approach can be used for modelling a manufacturing system based on a number of conflicting objectives (energy consumption, $\mathrm{CO}_{2}$ emissions and costs in this study) in which each of objectives needs to be optimised using an objective function. Sahar et al. [10] proposed a multi-objective optimization model of a two-layer dairy supply chain aimed at minimizing $\mathrm{CO}_{2}$ emissions of 
transportation and the total cost for product distribution. Abdallah et al. [11] have utilized a multi-objective optimization method used for minimizing carbon emissions and investment cost of the supply chain network facilities. Wang et al. [12] studied a multi-objective optimization model that balances the trade-off between total cost and the amount of $\mathrm{CO}_{2}$ emissions released from the supply chain facilities. Jamshidi et al. [13] developed a multi-objective mathematical model to solve a number of issues of a supply chain design in terms of minimization of annual cost with a due consideration over environmental effect. Shaw et al. [14] proposed an integrated approach for selecting the appropriate supplier in the supply chain through development of a fuzzy multi-objective linear programming that address the minimization of ordered quantity to the supplier and the minimization of the total carbon emissions for sourcing of material.

This paper presents a study through the development of a multi-objective model, which was used for examining the configuration of the proposed sustainable manufacturing system design seeking a compromised solution among conflicting objectives. The aim of objectives was to minimize the total investment cost for establishing the manufacturing system, the amount of energy consumed by the machines involved in each process and the $\mathrm{CO}_{2}$ emissions released from the machines involved in each process within the manufacturing system. The developed model was coded using LINGO $^{11}$ in which non-inferior solutions were obtained using the $\varepsilon$-constraint approach; followed by an employment of the max-min approach in order to select the best non-inferior solution.

\section{PROBLEM STATEMENT AND MODEL FORMULATION}

Figure 1 illustrates the sustainable manufacturing system design in which three facilities were considered, these are supplier $s$, factory $f$ and warehouse $w$. The facility may consist of operation machines, air conditioning units, lighting bulbs and other supportive equipment such as compressors that supply compressed air to some operation machines. Between facilities, there are transportation vehicles to be used. To achieve the sustainability of a manufacturing system design, energy consumed by all those equipment in the manufacturing system as well as the amount of $\mathrm{CO}_{2}$ emissions released from the manufacturing system need to be quantified in conjunction with the total cost that also needs to be considered for establishing the manufacturing system. To this aim, these parameters are mathematically formulated as a multi-objective optimization model aimed at obtaining a trade-off decision among minimization of total investment cost for establishing the manufacturing system (equation 1), minimization of the total energy consumed by the manufacturing system (equation 2 ), and minimization of the total amount of $\mathrm{CO}_{2}$ emissions (equation 3) as described below. These objectives are in conjunction with (i) numbers of operation machines and (ii) quantity of materials flows in the manufacturing system.

The authors wish to thank the Higher Committee for Education Development in Saudi Arabia for the financial support to this study.

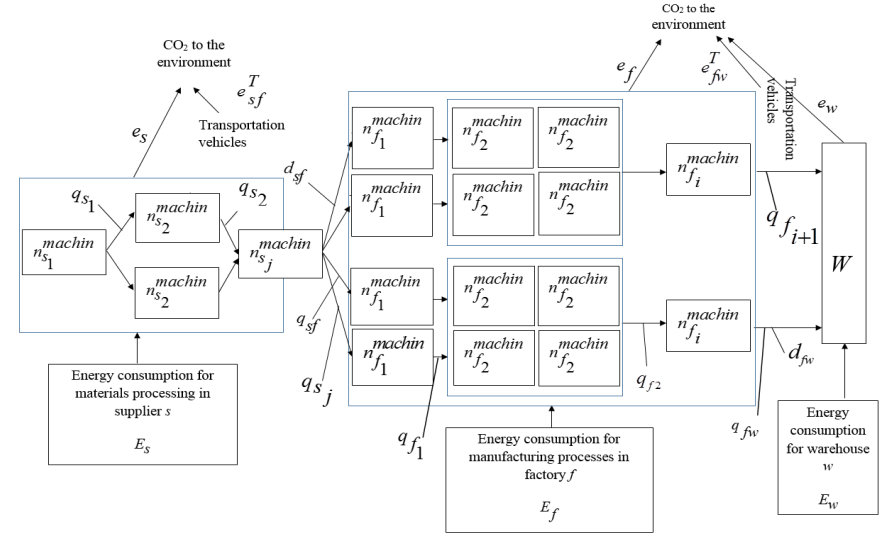

Fig. 1. Configuration of the sustainable manufacturing system design

The following notations which includes sets, parameters and decision variables are used for formulating the mathematical model:

\section{Sets:}

$S$

\section{$f$}

$W$

$m_{s_{j}}, m_{f_{i}}$

Parameters

$C_{l}^{\text {Fixed }}$

$C_{S}^{R}$

$C_{s f}^{R}$

$C_{f}^{M P}$

$C_{f w}^{M P}$

$C_{w}^{I}$

$C_{f w}^{I}$

$C_{l}^{T}$ set of supplier

set of manufacturing system

set of warehouse

number of manufacturing processes involved

in supplier $s$ and in factory $f$ respectively

where $j \in\left\{1,2, \ldots, m_{s_{j}}\right\}$ and $i \in\left\{1,2, \ldots, m_{f_{i}}\right\}$

fixed cost (GBP) of facility $l$, where

$l \in\{s, f, w\}$

unit raw materials cost (GBP) in supplier $s$

raw materials cost (GBP) from supplier $s$ to factory $f$

unit manufacturing product cost (GBP) at factory $f$

manufacturing product cost (GBP) from

factory $f$ to warehouse $w$

unit inventory cost (GBP) per product at warehouse $w$

inventory cost (GBP) from factory $f$ to

warehouse $w$

Cost of transportation of raw materials

per mile between facilities $l$, where $l \in\{s, f, w\}$ 


$$
\begin{aligned}
& C_{s f}^{T}, C_{f w}^{T} \quad \text { unit transportation cost (GBP) per mile from } \\
& \text { supplier } s \text { to factory } f \text { and from factory } f \\
& \text { to warehouse } w \text { respectively } \\
& d_{s f}, d_{f w} \quad \text { distance (miles) from supplier } s \text { to factory } f \\
& \text { and from factory } f \text { to warehouse } w \\
& C a_{l} \quad \text { maximum capacity }(\mathrm{kg}) \text { of facility } l \text {, } \\
& \text { where, } l \in\{s, f, w\} \\
& D_{f}, D_{w} \\
& \text { minimum demand }(\mathrm{kg}) \text { of factory } f \text { and } \\
& \text { of warehouse } w \\
& E_{S}, E_{f} \\
& \text { and } E_{w} \\
& E_{s_{j}}^{\text {machin }} \\
& \text { energy consumption (kWh) for supplier } s \text {, } \\
& \text { for factory } f \text { and for warehouse } w \text { respectively } \\
& \begin{array}{cc}
\text { air } & \text { air } \\
N_{s_{j}}^{\text {comp }}, & N_{f_{i}}^{\text {comp }} \\
N_{s_{j}}^{\text {cond }},{ }^{\text {cond }} & N_{f_{i}}^{\text {cond }}
\end{array} \\
& \text { installed power }(\mathrm{kw}) \text { for a compressor in } \\
& \text { supplier } s \text { and in factory } f \text { respectively } \\
& \text { installed power }(\mathrm{kw}) \text { for an air conditioning } \\
& \text { unit involved in process } j \text { in supplier } s \text { and } \\
& \text { in process } i \text { in factory } f \text { respectively } \\
& N_{s_{j}}^{b u l b}, N_{f_{i}}^{b u l b} \\
& \text { installed power (kw) for a lighting bulb } \\
& \text { involved in process } j \text { in supplier } s \text { and } \\
& \text { in process } i \text { in factory } f \text { respectively } \\
& \wp_{S}, \wp_{f} \\
& \text { and } \wp_{w} \\
& \Psi_{S_{j}}, \Psi_{f_{i}} \\
& \text { energy consumption ( } \mathrm{kWh} \text { ) for a machine } \\
& \text { involved in process } j \text { in supplier } s \text { and } \\
& \text { in process } i \text { in factory } f \text { respectively, where } \\
& E_{f_{i}}^{\text {machin }} \\
& E_{S}^{\text {air comp }} \text {, energy consumption (kWh) of compressed air } \\
& j \in\left\{1,2, \ldots, m_{s_{j}}\right\} \text { and } i \in\left\{1,2, \ldots, m_{f_{i}}\right\} \quad v_{f_{i}}^{\text {air comp }}
\end{aligned}
$$

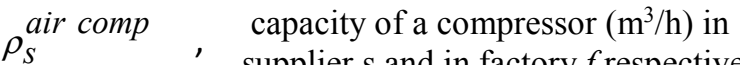

$$
\begin{aligned}
& \text { needed for a machine involved in process } j \\
& \text { in supplier } s \text { and in process } i \text { in factory } f \\
& E_{f_{i}}^{\text {air comp }} \\
& E_{s_{j}}^{c o n d}, E_{f_{i}}^{c o n d} \\
& \text { respectively } \\
& \text { energy consumption }(\mathrm{kWh}) \text { for the } \\
& \text { air conditioning units involved in process } j \\
& \text { in supplier } s \text { and in process } i \text { in factory } f \\
& \text { respectively } \\
& E_{s}^{b u l b}, E^{b u l b} \text { energy consumption (kWh) for the lighting } \\
& \text { bulbs involved in process } j \text { in supplier } s \\
& \text { in process } i \text { in factory } f \text { respectively } \\
& E_{w}^{c o n d}, E_{w}^{b u l b} \\
& \text { energy consumption }(\mathrm{kWh}) \text { for the air } \\
& \text { conditioning units and lighting } \\
& \text { bulbs in warehouse } w \text { respectively }
\end{aligned}
$$

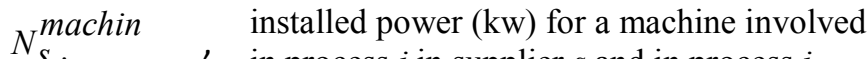

$$
\begin{aligned}
& N_{s} \quad, \quad \text { in process } j \text { in supplier } s \text { and in process } i \\
& N_{\text {machin }} \quad \text { in factory } f \text { respectively } \\
& f_{i} \\
& \Re_{s_{j}}, \Re_{f_{i}} \quad \text { manufacturing rate }(\mathrm{kg} / \mathrm{h}) \text { for a machine } \\
& \text { involved in process } j \text { in supplier } s \text { and } \\
& \text { in process } i \text { in factory } f \text { respectively } \\
& \tau_{s_{j},} \tau_{f_{i}} \\
& \mu_{s_{j}}, \mu_{f_{i}} \\
& \varphi_{S_{j}}^{b u l b} \varphi_{f_{i}}^{b u l b} \\
& \Pi_{w}^{c o n d} \\
& \lambda_{w}^{b u l b} \\
& \rho_{f}^{\operatorname{air} \text { comp }} \\
& \Phi_{s_{j}}^{\text {cond }}, \Phi_{f_{i}}^{\text {cond }} \\
& \text { mass production (kg/month) from supplier } s \text {, } \\
& \text { from factory } f \text { and in warehouse } w \text { respectively } \\
& \text { total waste ratio }(\%) \text { for a machine involved } \\
& \text { in process } j \text { in supplier } s \text { and } \\
& \text { in process } i \text { in factory } f \text { respectively } \\
& \text { compressed air per } \mathrm{h}\left(\mathrm{m}^{3} / \mathrm{h}\right) \text { used for } \\
& \text { a machine involved in process } j \text { in supplier } s \\
& \text { and in process } i \text { in factory } f \text { respectively }
\end{aligned}
$$

$e_{S} e_{f}$
and $^{e} w$
$e^{T}$




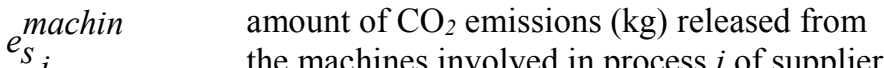

$$
\begin{aligned}
& \text { the machines involved in process } j \text { of supplier } \\
& \text {, } s \text { and in process } i \text { of factory } f \text { respectively } \\
& e_{f}^{\operatorname{machin}}
\end{aligned}
$$

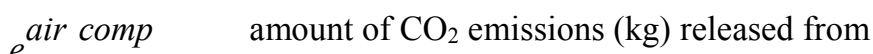

$$
\begin{aligned}
& e_{s} \quad \text { a compressor system involved in process } j \\
& e_{f_{i}}^{\text {air comp }} \quad \text { of supplier } s \\
& \text { cond amount of } \mathrm{CO}_{2} \text { emissions }(\mathrm{kg}) \text { released from } \\
& e_{s} \quad \text { the air conditioning units involved in } \\
& \text { cond } \quad \text { process } j \text { of supplier } s \text { and in process } i \\
& e_{f_{i}}^{c o n d} \quad \text { of factory } f \text { respectively } \\
& \text { bulb bulb amount of } \mathrm{CO}_{2} \text { emissions (kg) released from } \\
& e_{s}, e_{i} \quad \text { the lighting bulbs involved in process } j \\
& \text { of supplier } s \text { and in process } i \text { of factory } f \\
& \text { respectively } \\
& e_{s f}^{T}, e_{f w}^{T} \\
& V \quad \text { capacity (units) per vehicle } \\
& \omega_{j}^{s}, \omega_{i}^{f} \quad \mathrm{CO}_{2} \text { emission factor }(\mathrm{kg} / \mathrm{kWh}) \text { in supplier } s \\
& \text { and in factory } f \text { respectively } \\
& \omega^{T}, \omega^{T} \quad \mathrm{CO}_{2} \text { emission factor }(\mathrm{kg} / \mathrm{mile}) \text { released } \\
& \text { for transportation from supplier } s \text { to } \\
& \text { factory } f \text { and from factory } f \text { to warehouse } w \\
& \text { respectively } \\
& \text { respectively where, } j \in\left\{1,2, \ldots ., m_{s}\right\} \\
& \text { and } i \in\left\{1,2, \ldots, m_{f_{i}}\right\} \\
& n_{s_{j}}^{\text {machin }} \\
& \text { Min } Z_{1}=C_{s}^{\text {Fixed }}+C_{f}^{\text {Fixed }}+C_{w}^{\text {Fixed }}+C_{s}^{R} q_{s f} \\
& +C_{f}^{M . P} q_{f w}+C_{s f}^{T} \frac{q_{s f}}{V} d_{s f}+C_{f w}^{T} \frac{q_{f w}}{V} d_{f w}+C_{w}^{I} q_{f w}
\end{aligned}
$$

\section{Decision variables}

\section{Objective function 1: total investment $\operatorname{cost} Z_{1}$}

\section{Objective function 2: total energy consumption $Z_{2}$}

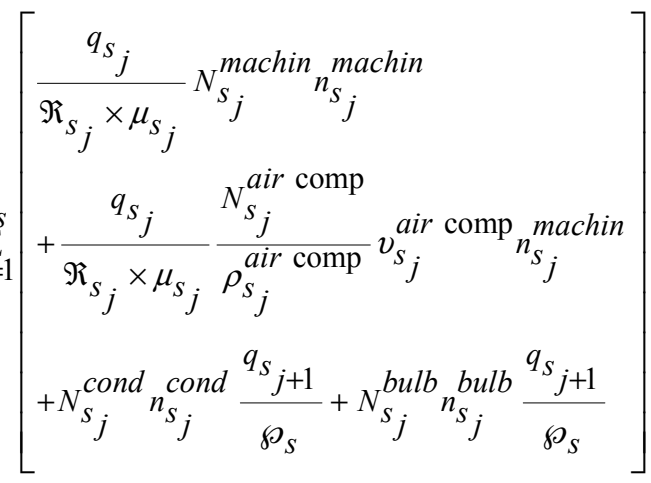

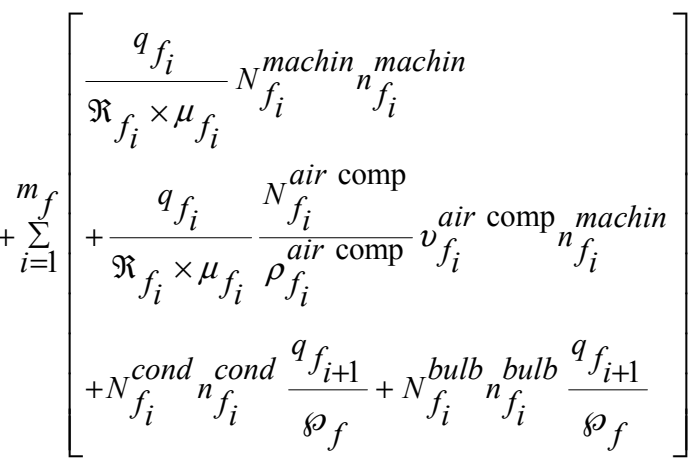

$$
\begin{aligned}
& +\left[N_{w}^{\text {cond }} n_{w}^{\text {cond }} \frac{q_{w}}{\wp_{w}}+N_{w}^{\text {bulb }} n_{w}^{\text {bulb }} \frac{q_{w}}{\wp_{w}}\right]
\end{aligned}
$$




\section{Objective function 3: total $\mathrm{CO}_{2}$ emissions $Z_{3}$}

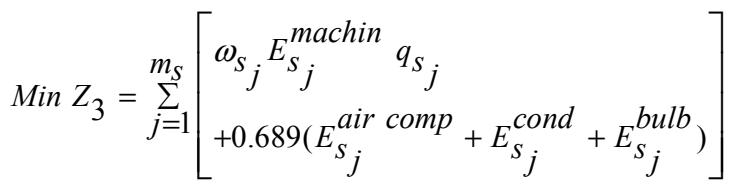

$+\omega_{s f}^{T} \frac{q_{s f}}{V} d_{s f}+\omega_{f w}^{T} \frac{q_{f w}}{V} d_{f w}$

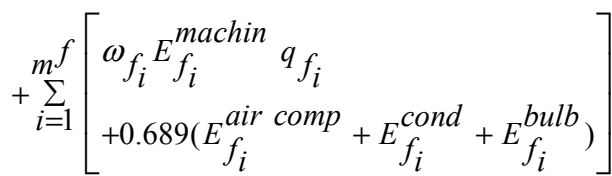

$+0.689\left(E_{w}^{\text {cond }}+E_{w}^{b u l b}\right)$

Where, the $\mathrm{CO}_{2}$ emission factor $\omega_{s_{j}}, \omega_{f_{i}}$ and $\omega_{s f, f w}^{T}$ is shown in Table I $[15,16]$.

TABLE I. AMOUNT OF $\mathrm{CO}_{2}$ EMISSION FACTOR PER KWH AND PER MILE.

\begin{tabular}{|c|c|c|}
\hline Energy source & $\begin{array}{c}\text { Emission factor } \omega_{s_{j}}, \\
\omega_{f_{i}} \text { and } \omega_{w} \\
(\mathrm{~kg} / \mathrm{kWh})\end{array}$ & $\begin{array}{l}\text { Emission factor } \\
\omega_{s f, f w}^{T} \text { for truck } \\
\quad(\mathrm{kg} / \mathrm{mile})\end{array}$ \\
\hline $\begin{array}{l}\text { Oil as indirect energy source } \\
\text { to generate electricity }\end{array}$ & 0.6895 & 0.420 \\
\hline
\end{tabular}

Constraints:

$q_{s f} \leq \mathrm{Ca} f$

$q_{f w} \leq C a_{w}$

$q_{s f} \geq D_{f}$

$q_{f w} \geq D_{w}$

$\left(1-\Psi_{S_{j}}\right) q_{S_{j}} \geq q_{S(j+1)}$

$\left(1-\Psi_{f_{i}}\right) q_{f_{i}} \geq q_{f_{(i+1)}}$

$\Phi_{s_{j}}^{\text {cond }} n_{S_{j}}^{\text {cond }} \geq n_{s_{j}}^{\text {machin }}$

$\Phi_{f_{i}}^{\text {cond }} n_{f_{i}}^{\text {cond }} \geq n_{f_{i}}^{\text {machin }}$

$n_{s_{j}}^{\text {bulb }} \geq \varphi_{s_{j}}^{\text {bulb }} n_{s_{j}}^{\text {machin }}$

$$
\begin{aligned}
& n_{f_{i}}^{\text {bulb }} \geq \varphi_{f_{i}}^{\text {bulb }} n_{f_{i}}^{\text {machin }} \\
& \Pi_{w^{\prime}} n_{w}^{\text {cond }} \geq q_{f w} \\
& \lambda_{w_{w}} n^{\text {bulb }} \geq q_{f w} \\
& q_{s_{j}}, q_{s f}, q_{f_{i}}, q_{f w} \geq 0 \\
& \Re_{s_{j}}{ }_{n_{j}^{\text {machin }}} \geq q_{S_{(j+1)}} \\
& \Re_{f_{i}}{ }_{f_{i}}^{\text {machin }} \geq q_{f_{(i+1)}}
\end{aligned}
$$

Where, equations 4, 5, 6, 7, 8, 9 and 16 are quantity constraints; and equation 10-15, 17 and 18 are constraints in numbers of machines, air conditioning units and bulbs.

\section{APPLICATION AND EVALUATION}

In order to examine the applicability and the validation of the developed multi-objective optimisation model as described above, a real case study was applied. The sustainable manufacturing system consists of three facilities (supplier $s$, factory $f$ and warehouse $w$ ), and each facility has different processing tasks, each process task may involve a number of machines, number of air conditioning units and number of illumination bulbs. Each of those equipment has consumption of energy, releases an amount of $\mathrm{CO}_{2}$ emissions and has mass inputs with different specifications. The study was carried out by analysing the total cost for establishing these facilities, the energy consumption and the amount of $\mathrm{CO}_{2}$ emissions towards a sustainable manufacturing design.

Table II shows the collected data were taken from a real manufacturing system which includes three facilities (1 supplier, 1 factory and 1 warehouse) used for producing plastic and woven sacks. In this case, the production line is powered by electricity which is generated using oil as indirect source of energy. LINGO ${ }^{11}$ software was used for computing results based on the developed multi-objective mathematical model aiming to seek the optimization solutions. In aiming to obtain non-inferior solutions, $\varepsilon$-constraint approache was utilized [17]. In this approach, the developed multi-objective model can be converted into a single-objective by adding constraints; the higher priority objective (total energy consumption) is considered to be an objective function (equation 19) and the other two objective functions (the total cost and the total $\mathrm{CO}_{2}$ emissions) are shifted to be $\mathcal{E}$-based constraints; i.e. which (equation 20) restricts the value of the first objective function to be less than or equal to $\varepsilon_{l}$ which gradually varies between the minimum value and the maximum value for objective function one (equation 21). Equation 22 restricts the value of the third objective function to be less than or equal to $\varepsilon_{2}$ which gradually varies between the minimum value and the maximum value for objective function three (equation 23). The equivalent solution formula $\mathrm{Z}$ is presented as follows 
Proceedings of the 23rd International Conference on Automation \& Computing, University of Huddersfield, Huddersfield, UK, 7-8 September 2017

\section{$\operatorname{Min}_{2}$}

Eq. (19) is subject to the following constrains:

$Z_{1} \leq \varepsilon_{1}$

$\left(Z_{1}\right)^{\min } \leq \varepsilon_{1} \leq\left(Z_{1}\right)^{\max }$

$Z_{3} \leq \varepsilon_{2}$

$\left(Z_{3}\right)^{\min } \leq \varepsilon_{2} \leq\left(Z_{3}\right)^{\max }$

And additional constraints including (equation. 4-18)

Table III, illustrates the non-inferior solutions that were obtained by an assignment of $\varepsilon$-values from $20,781,782$ to $26,000,000$ for objective one and from $103.75 \times 10^{9}$ to $158.75 \times 10^{9}$ for objective three. It can be noted in Table III that the values of objective one and three are highly corresponding to the assigned values of $\varepsilon_{1}$ and $\varepsilon_{2}$ which vary between the minimum and maximum value for objectives one and three, respectively. As an example, solution 1 obtained by an assignment of $\varepsilon_{1}=20,781,782$, and $\varepsilon_{2}=103.75 \times 10^{9}$ accordingly, the minimum total cost for establishing the manufacturing system is $20,500,000 \mathrm{GBP}$, the minimum total amount of energy consumed by the manufacturing system is $2,357,288$ $\mathrm{kWh}$ and the minimum total amount of $\mathrm{CO}_{2}$ emissions released from the manufacturing system is $103748 \times 10^{6} \mathrm{~kg}$.

TABLE II. DATA COLLECTED FROM A PLASTIC AND WOVEN SACKS COMPANY

\begin{tabular}{|c|c|c|}
\hline \multicolumn{3}{|c|}{ Facilities } \\
\hline Supplier $s$ & Factory $f$ & Warehouse $w$ \\
\hline$C_{s}^{\text {Fixed }}$ (GBP): 5000000 & $C_{f}^{\text {Fixed }}(\mathrm{GBP}): 6000000$ & $C_{w}^{\text {Fixed }}(\mathrm{GBP}): 2000000$ \\
\hline$C_{s}^{R}(\mathrm{GBP} / \mathrm{kg}): 2$ & $C_{f}^{M \cdot P}(\mathrm{GBP} / \mathrm{kg}): 3$ & $C_{w}^{I}(\mathrm{GBP} / \mathrm{kg}): 2$ \\
\hline$C_{s f}^{T}$ (GBP/mile): 2 & $C_{f w}^{T}$ (GBP/mile): 2 & \\
\hline$d_{s f}$ (mile): $50, V(\mathrm{~kg}): 20000$ & $d_{f w}($ mile): $10, V=20000$ & \\
\hline \multirow[t]{2}{*}{$C a_{S}$ (kg month): 1000000} & $\mathrm{Ca} a_{f}$ (kg/month): 990,000 & $C a_{w}$ (kg/month): 900000 \\
\hline & $D_{f}$ (kg/month): 850000 & $D_{w^{\text {(kg/month): }} 850000}$ \\
\hline$m_{s}=4$ process & $m_{f}=8$ process & \\
\hline $\begin{array}{l}\Re_{S_{j}}(\mathrm{~kg} / \mathrm{h}): 1976,1936,1932 \text { and } 1929, \\
\text { where } j \in\left\{1,2, \ldots . ., m_{s}\right\}\end{array}$ & $\begin{array}{l}\Re_{f_{i}}(\mathrm{~kg} \mathrm{~h}): 1852,1815,1742,1716,1699,1665 \text {, } \\
1660 \text { and } 1643 \text {, where } i \in\left\{1,2, \ldots, m_{f}\right\}\end{array}$ & \\
\hline$\mu_{s j}(\%): 80$ for all machines & $\mu_{f_{i}}(\%): 80$ for all machines & \\
\hline$\Psi_{s_{j}}(\%): 0.03,0.02,0.002,0.15$ & $\Psi_{f_{i}}(\%): 0.02,0.04,0.015,0.01,0.02,0.003,0.01,0$ & \\
\hline$N_{s_{j}}^{m a c h i n}(\mathrm{kww}): 700,500,300,600$ & 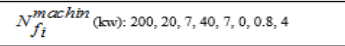 & \\
\hline$N_{s_{j}}^{\text {air comp }}(\mathrm{kww}): 0$ & $N_{f_{i}}^{\text {air comp }}(\mathrm{kww}): 200$ & \\
\hline$\rho_{s j}^{a p^{\prime}} \operatorname{comp}{ }_{\left(\mathrm{m}^{\mathrm{3}} / \mathrm{h}\right): 0}$ & $\rho_{f_{i}}^{a i r \operatorname{comp}}\left(\mathrm{m}^{\mathrm{3} / \mathrm{h}): 666}\right.$ & \\
\hline$v_{s_{j}}^{\text {air comp }}\left(\mathrm{m}^{3} / \mathrm{h}\right): 0$ & $v_{f_{i}}^{\text {air comp }}\left(\mathrm{m}^{3} / \mathrm{h}\right): 5,4,13,0,7,5,20,0,0,0$ & \\
\hline$N_{s_{j}}^{\text {cond }}(\mathrm{kw}): 2.2$ & $N_{f_{i}}^{c o n d}(\mathrm{kw}): 2.2$ & $N_{w}^{\text {cond }}(\mathrm{kww}): 2.2$ \\
\hline$N_{s_{j}}^{\text {bulb }}(\mathrm{kav}): 0.4$ & $N_{f_{i}}^{\text {bulb }}(\mathrm{kwv}): 0.4$ & $N_{w}^{\text {bulb }}(\mathrm{kww}): 0.4$ \\
\hline$\Phi_{S_{j}}^{\text {cond }}{\text { (umits): } 2, \varphi_{s_{j}}^{\text {bulb }} \text { (umits): } 15}$ & $\Phi_{f_{i}}^{\text {cond } \text { (units) }_{2}, \varphi_{f_{i}}^{\text {bulb }} \text { (units): } 15}$ & $\begin{array}{l}\Pi_{w}^{\text {cond }}(\mathrm{kg}): 1000, \lambda_{w}^{\text {bulb }} \\
(\mathrm{kgg}): 500\end{array}$ \\
\hline$f_{s}(\mathrm{kgg}): 950000$ & $\mathfrak{f}_{f}(\mathrm{kgg}): 840000$ & $\wp_{w}$ (units): $9,032,258$ \\
\hline$\omega_{s j}(\mathrm{~kg} / \mathrm{kWh})=0.6895$ & 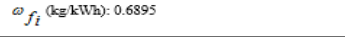 & $\omega_{w}(\mathrm{~kg} / \mathrm{kWh})=0.6895$ \\
\hline$\omega_{s f}^{T}(\mathrm{~kg}$ mile) $: 0.420$ & $\omega_{f w}^{T}(\mathrm{~kg} / \mathrm{mile})=0.420$ & \\
\hline
\end{tabular}

TABLE III. NON-INFERIOR SOLUTIONS OBTAINED BY USING THE $\mathcal{E}$ CONSTRAINT APPROACH

\begin{tabular}{|c|c|c|c|l|l|}
\hline \multirow{2}{*}{$\begin{array}{c}\text { Solution } \\
\text { number }\end{array}$} & \multicolumn{2}{|c|}{$\varepsilon$-values } & \multicolumn{3}{c|}{ Objective function solutions } \\
\cline { 2 - 6 } & $\varepsilon_{1}$ & $\varepsilon_{2}$ & Min $Z_{1}$ & $\operatorname{Min} Z_{2}$ & Min $Z_{3}$ \\
\hline 1 & 20781782 & $103.75 \times 10^{9}$ & 20500000 & 2357288 & $103748 \times 10^{6}$ \\
\hline 2 & 22123925 & $117.5 \times 10^{9}$ & 21879729 & 2557194 & $117498 \times 10^{6}$ \\
\hline 3 & 23466068 & $131.25 \times 10^{9}$ & 23239639 & 2842852 & $131248 \times 10^{6}$ \\
\hline 4 & 24808211 & $145 \times 10^{9}$ & 24640700 & 3128510 & $144998 \times 10^{6}$ \\
\hline 5 & 26000000 & $158.75 \times 10^{9}$ & 26000000 & 3414168 & $158748 \times 10^{6}$ \\
\hline
\end{tabular}

As shown in Table IV, each solution has a potential group of number of machines that is involved in process $j$ in supplier $s_{\left(n_{s_{j}}^{\text {machin }}\right)}$ where $j \in\{1,2,3,4\}$. For instance, in solution 1 , number of machines involved in process task $j$ is $(1,1,1,1)$.

TABLE IV. NUMBERS OF MACHINES INVOLVED IN PROCESS $J$ IN SUPPLIER $S$ UNDER THE $\mathcal{E}$-CONSTRAINT APPROACH

\begin{tabular}{|c|c|c|c|c|}
\hline $\begin{array}{l}\text { Solution } \\
\text { number }\end{array}$ & \multicolumn{4}{|c|}{$\begin{array}{c}\text { Numbers of machines involved in process } j, \\
n_{s_{j}}^{\text {machin }} \\
\text { Where } \\
j \in\{1,2,3,4\} .\end{array}$} \\
\hline & $n_{s 1}$ & $n_{s 2}$ & $n_{s 3}$ & $n_{s 4}$ \\
\hline 1 & 1 & 1 & 1 & 1 \\
\hline 2 & 1 & 1 & 1 & 1 \\
\hline 3 & 2 & 2 & 1 & 1 \\
\hline 4 & 2 & 2 & 2 & 1 \\
\hline 5 & 2 & 2 & 1 & 2 \\
\hline
\end{tabular}

Table $\mathrm{V}$ shows the result for solution 1 using the $\varepsilon$ constraint approach which gives the group of machines involved in process $i$ in factory $f\left(n_{f_{i}}^{\text {machin }}\right)$ where $i \in\{1,2,3,4,5,6,7,8\}$ is $(4,32,3,5,9,9,35,3)$.

TABLE V. NUMBERS OF MACHINES INVOLVED IN PROCESS $I$ IN FACTORY F UNDER THE $\mathcal{E}$-CONSTRAINT APPROACH

\begin{tabular}{|c|c|c|c|c|c|c|c|c|}
\hline \multirow{2}{*}{$\begin{array}{l}\text { Solution } \\
\text { number }\end{array}$} & \multicolumn{7}{|c|}{$\begin{array}{c}\text { Numbers of machines involved in process } i, \\
n_{i} \text { machin }\end{array}$} \\
& \multicolumn{8}{|c|}{$i \in\{1,2,3,4,5,6,7,8\}}$. \\
\hline & $n_{f 1}$ & $n_{f 2}$ & $n_{f 3}$ & $n_{f 4}$ & $n_{f 5}$ & $n_{f 6}$ & $n_{f 7}$ & $n_{f 8}$ \\
\hline 1 & 4 & 32 & 3 & 5 & 9 & 9 & 35 & 3 \\
\hline 2 & 4 & 32 & 3 & 5 & 10 & 10 & 40 & 3 \\
\hline 3 & 4 & 40 & 3 & 5 & 13 & 13 & 60 & 4 \\
\hline 4 & 5 & 40 & 4 & 5 & 14 & 14 & 60 & 4 \\
\hline 5 & 5 & 45 & 5 & 6 & 16 & 16 & 60 & 5 \\
\hline
\end{tabular}

A pairwise comparison among the three conflicting objectives is illustrated in Figure 2a and $2 \mathrm{~b}$. The results shown 
in Figure $2 \mathrm{a}$ and $2 \mathrm{~b}$ indicate that the non-inferior solution 1 gives values of the total cost, the total energy consumption and total $\mathrm{CO}_{2}$ emissions less compared to the other solutions. Additionally, as indicated in Tables IV and V that the noninferior solution 1 in terms of number of machines that need to be involved in supplier $s$ and factory $f$, gives values less than the other solutions. By balancing the three objectives with of $\varepsilon_{1}=20,781,782$, and $\varepsilon_{2}=103.75 \times 10^{9}$, it leads to compromise solution 1, which includes an installation of machines that need to be involved in processes task $j$ in supplier $s$ where, $j \epsilon$ $(1,2,3,4)$ is $(1,1,1,1)$, and installation of machines that need to be involved in processes task $i$ in factory $f$ where, $i \in(1,2,3$, $4,5,6,7,8)$ is $(4,32,3,5,9,9,35,3)$. This solution gives a minimum total cost for establishing the manufacturing system is $(20,500,000) \mathrm{GBP}$, the minimum total amount of energy consumed by the manufacturing system is $(2,357,288) \mathrm{kWh}$ and the minimum total amount of $\mathrm{CO}_{2}$ emissions released from the manufacturing system is $\left(103748 \times 10^{6}\right) \mathrm{kg}$.

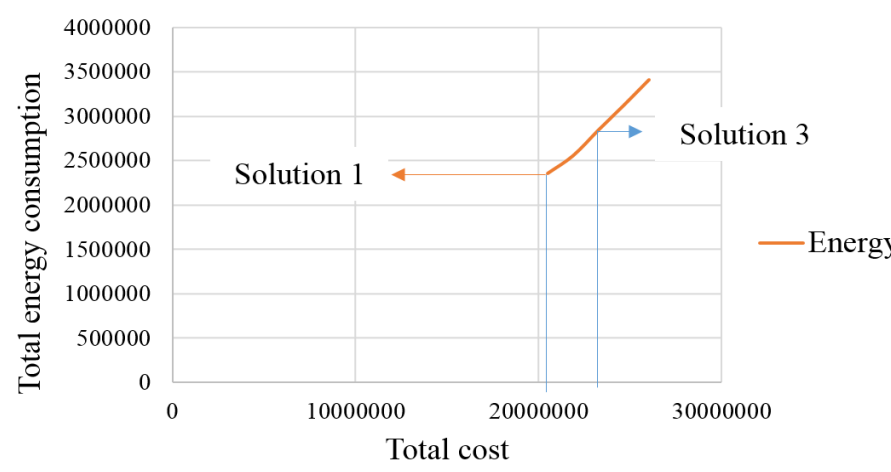

a

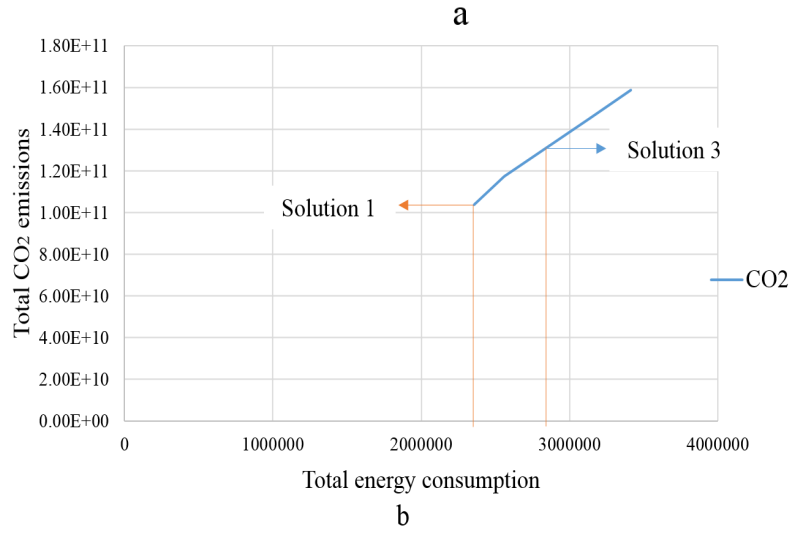

Fig. 2. Comparison between solutions obtained

In order to design a sustainable manufacturing system based on the obtained solutions using the $\varepsilon$-constraint approach, one of these solutions needs to be selected based on the preferences of decision makers or using the Max-Min approach [18]. Based on this Max-Min approach, although solution 1 has less values of the total cost, the total energy consumption, total $\mathrm{CO}_{2}$ emissions and number of machines than the other solutions, solution 3 is determined as the best solution as it has the minimal distance 3.45 to the value of the ideal solution. Table VI shows the optimal solutions in quantity of material flows (i) among the machines involved in process task $j$ in supplier $s$ (ii) from supplier $s$ to factory $f$ (iii) among the machines involved in process task $i$ in factory $f$ and (iv) from factory $f$ to warehouse $w$.

TABLE VI. THE OPTIMAL QUANTITY OF MATERIAL FLOW FOR THE SUSTAINABLE MANUFACTURING SYSTEM DESIGN

\begin{tabular}{|c|c|c|c|c|c|c|c|c|c|}
\hline \multicolumn{10}{|c|}{ Supplier $s$} \\
\hline \multirow[t]{2}{*}{$\begin{array}{l}\text { Solution } \\
\text { number }\end{array}$} & \multicolumn{4}{|c|}{$q_{S}{ }_{j}$ where ${ }_{j \in\{1,2,3,4\}}$} & \multirow[t]{2}{*}{$q_{s f}$} & & & & \\
\hline & $q_{s l}$ & $q_{: 2}$ & $q_{s 3}$ & $q_{s 4}$ & & - & - & - & - \\
\hline 1 & 940300 & 935200 & 933090 & 928184 & 915358 & - & - & - & \\
\hline 2 & 955355 & 950050 & 948100 & 946084 & 934570 & - & - & - & - \\
\hline 3 & 985500 & 965200 & 963040 & 960084 & 935805 & - & - & - & - \\
\hline 4 & 1000000 & 980000 & 978040 & 976084 & 937040 & - & - & - & - \\
\hline 5 & 1020000 & 1002000 & 996100 & 994084 & 955150 & - & - & - & - \\
\hline 6 & 1045000 & 1027000 & 1009000 & 991100 & 973050 & - & - & - & - \\
\hline 7 & 1066000 & 1048000 & 1033000 & 1015000 & 997040 & - & - & - & - \\
\hline 8 & 1083000 & 1065000 & 1047050 & 1029100 & 1014100 & - & - & - & - \\
\hline \multicolumn{9}{|c|}{ Factory $f$} & $\begin{array}{c}\text { Warehouse } \\
w\end{array}$ \\
\hline \multirow[t]{2}{*}{$\begin{array}{l}\text { Solution } \\
\text { number }\end{array}$} & \multicolumn{8}{|c|}{${ }^{q} f_{i}$ where $i \in\{1,2,3,4,5,6,7,8\}$} & $q_{f w}$ \\
\hline & $q_{f 1}$ & $q_{52}$ & $q_{\beta}$ & $q_{f 4}$ & $q_{f 5}$ & $q_{f 6}$ & $q_{f 7}$ & $q_{f f}$ & \\
\hline 1 & 918358 & 900100 & 852898 & 832220 & 810660 & 633131 & 580407 & 550100 & $\begin{array}{l}5,915,053 \\
\text { sacks }\end{array}$ \\
\hline 2 & 934570 & 902423 & 880500 & 842459 & 830550 & 730100 & 600010 & 580200 & $\begin{array}{l}6,238,709 \\
\text { sacks }\end{array}$ \\
\hline 3 & 935805 & 909227 & 881567 & 853478 & 842344 & 838459 & 790939 & 600100 & $\begin{array}{l}6,452,688 \\
\text { sacks }\end{array}$ \\
\hline 4 & 937040 & 918299 & 889824 & 868344 & 850660 & 840467 & 835940 & 831540 & $\begin{array}{l}8,941,290 \\
\text { sacks }\end{array}$ \\
\hline 5 & 955150 & 928300 & 904824 & 883344 & 865660 & 855467 & 850940 & 846540 & $\begin{array}{l}9,102,580 \\
\text { sacks }\end{array}$ \\
\hline 6 & 973050 & 940200 & 919700 & 898400 & 883660 & 870500 & 868940 & 864499 & $\begin{array}{c}9,295,688 \\
\text { sacks }\end{array}$ \\
\hline 7 & 997040 & 955100 & 934824 & 919344 & 901660 & 888399 & 886950 & 880550 & $\begin{array}{l}9,468,279 \\
\text { sacks }\end{array}$ \\
\hline 8 & 1014100 & 968188 & 952824 & 931344 & 916660 & 906467 & 904940 & 880555 & $\begin{array}{c}9,468,333 \\
\text { sacks }\end{array}$ \\
\hline
\end{tabular}

Table VII shows the result of solution 3 in terms of numbers of machines and the quantity of materials that need to be involved in the design of the sustainable manufacturing system. Figure 3 shows the optimal design of the sustainable manufacturing system based on solution 3 , which was obtained with $\varepsilon_{1}=23,466,068$, and $\varepsilon_{2}=131.25 \times 10^{9}$ that yields the minimum total cost of $23,239,639$ GBP, the minimum total amount of energy consumption of $2,842,852 \mathrm{kWh}$ and the minimum total amount of $\mathrm{CO}_{2}$ of $131,248 \times 10^{6} \mathrm{~kg}$.

TABLE VII. THE OPTIMAL SOLUTION FOR A SUSTAINABLE MANUFACTURING SYSTEM DESIGN

\begin{tabular}{|c|c|c|}
\hline $\begin{array}{c}\text { Process } \\
\text { number } J\end{array}$ & $\begin{array}{c}\text { Number of machines } \\
\text { involved in process } J \\
n_{s} \text { machin } \\
\text { units }\end{array}$ & $\begin{array}{c}\text { Quantity of materials } \\
\text { involved in process } j \\
\qquad q_{s} \\
(\mathrm{~kg})\end{array}$ \\
\hline 1 & 2 & 980000 \\
\hline 2 & 2 & 978040 \\
\hline 3 & 1 & 976084 \\
\hline 4 & 1 & 937040 \\
\hline & \multicolumn{2}{|c|}{ The optimal solution for factory $f$} \\
\hline $\begin{array}{l}\text { Process } \\
\text { number } \\
\bar{i}\end{array}$ & $\begin{array}{c}\text { Number of machines } \\
\text { involved in process } \bar{t} \\
m^{m} \text { achin } \\
f_{i} \\
\text { (units) }\end{array}$ & $\begin{array}{l}\text { Quantity of materials } \\
\text { involved in process } i \\
\qquad q_{f_{i}} \\
(\mathrm{~kg})\end{array}$ \\
\hline 1. & 4 & 937040 \\
\hline 2 & 40 & 918299 \\
\hline$\frac{2}{3}$ & 3 & 889824 \\
\hline 4 & 5 & 868344 \\
\hline 5 & 13 & 850660 \\
\hline 6 & 13 & 840467 \\
\hline 7 & 60 & 835940 \\
\hline 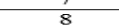 & 4 & 831540 \\
\hline Number o & $\begin{array}{l}\text { Mufacturing products } \\
\text { Ifiv } \\
\text { (units) }\end{array}$ & $8,941,290$ sacks \\
\hline
\end{tabular}




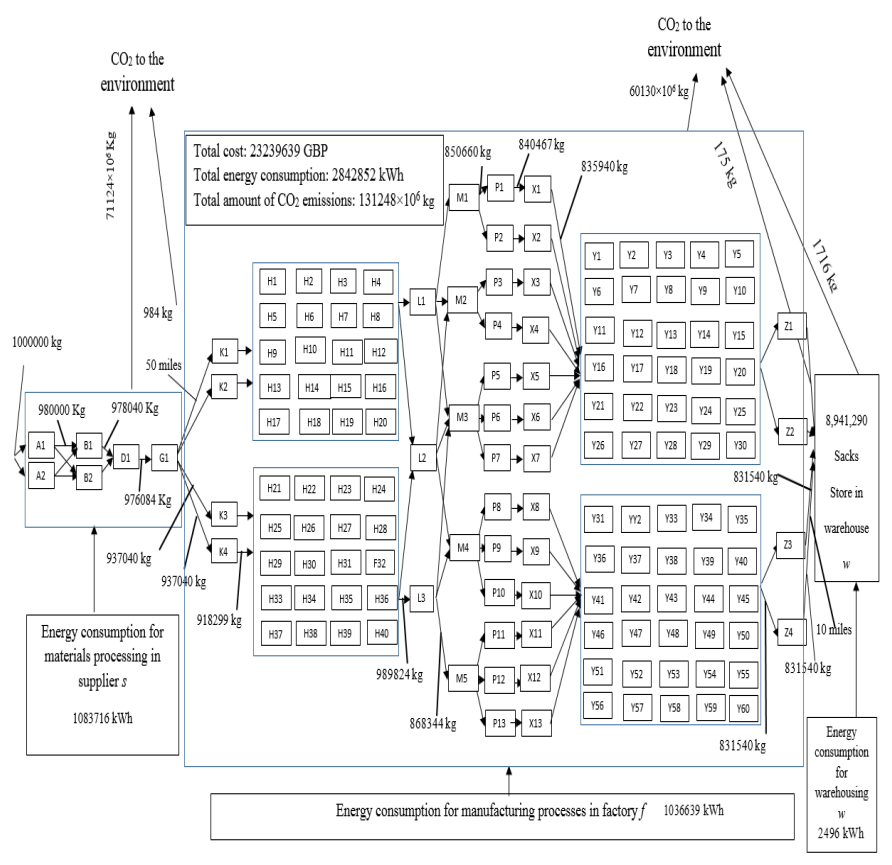

Fig. 3. An optimal sustainable manufacturing system design

\section{CONCLUSION}

When designing a manufacturing system, engineers used to focus on the key performance indicators in terms of such as system productivity and capacity; environmental considerations are often overlooked. This paper presents the development of a three-objective mathematical model as an aid for optimizing a sustainable manufacturing system design which addresses environmental sustainability relating to manufacturing activities. The developed multi-objective mathematical model can be used as a reference for manufacturing system designers to seek a trade-off solution in minimizing the total investment cost, minimizing the total energy consumption and minimizing the total $\mathrm{CO}_{2}$ emissions released from the manufacturing system. The computational results were validated based on data collected from a real industrial case. The study indicates that this is a useful and effective way as a decision-making tool used for optimizing a traditional manufacturing system design towards the sustainability under the economic and ecological constraints.

\section{REFERENCES}

[1] S. Lind, B. Krassi, B. Johansson, J. Viitaniemi, J. Heilala, S. Stahre, S. Vatanen, A. Fasth, and C. Berlin, "SIMTER: A Production Simulation Tool for Joint Assessment of Ergonomics, Level of Automation and Environmental Impacts", In the 18th FAIM, Stockholm, pp 5-49, 2008.

[2] M. Paju, J. Heilala, M. Hentula, A. Heikkila, B. Johansson, S. Leong, and K. Lyons, "Framework and indicators for a sustainable manufacturing mapping methodology", In the WSC, IEEE, Baltimore, MD, pp 3411-3422, 2010.

[3] H. Taghdisian, M. R. Pishvaie, and F. Farhadi, "Multiobjective optimization approach for green design of methanol plant based on CO2-efficeincy indicator," Journal of Cleaner Production, 2014.
[4] R. Nujoom, Q. Wang, and N. Bennett, "An Integrated Method for Sustainable Manufacturing Systems Design," In MATEC Web of Conferences, EDP Sciences, vol. 70, 2016, p. 05005, 2016a.

[5] Q. Wang, S. Lassalle, A. R. Mileham, and G. W, Owen, "Analysis of a linear walking worker line using a combination of computer simulation and mathematical modeling approaches," Journal of Manufacturing Systems, vol. 28, 2009, pp. 64-70.

[6] J. Heilala, S. Vatanen, H. Tonteri, J. Montonen, S. Lind, B. Johansson, and J. Stahre, "Simulation-based sustainable manufacturing system design," Proceedings of the 2008 Winter Simulation Conference, pp. 1922-1930, 2008.

[7] C. Wang, M. Larsson, C. Ryman, C. E. Grip, J. O. Wikström, A. Johnsson, and J. Engdahl, "A model on $\mathrm{CO} 2$ emission reduction in integrated steelmaking by optimization methods," IJER, vol. 32, pp. 1092-1106, 2008.

[8] M. Branham, T. G. Gutowski, A. Jones, and D. P. Sekulic, "A thermodynamic framework for analyzing and improving manufacturing processes," In ISEE. IEEE, San Francisco, CA, 2008, pp. 1-6.

[9] G. Guillén. Gosálbez, and I. E. Grossmann, "Optimal design and planning of sustainable chemical supply chains under uncertainty," AIChE Journal, vol. 55, No. 1, 2009, pp. 99-121.

[10] V. Sahar, B. Arijit, and P.J. Byrne, "A Case Analysis Of A Sustainable Food Supply Chain Distribution SystemA Multi-Objective Approach". International Journal of Production Economics, 152, pp71-87, 2014.

[11] T. Abdallah, A. Diabat, and D.Simchi-Levi, "A carbon sensitive supply chain network problem with green procurement", proceedings of the $40^{\text {th }}$ International Conference in Computers and Industrial Engineering (CIE), pp.1-6, IEEE.2010.

[12] F. Wang, X. Lai, and N. Shi, "A multi-objective optimization for green supply chain network design, Decision Support Systems, 51, 2011, pp. 262-269.

[13] R. Jamshidi, S. F, Ghomi, and B. Karimi, "Multiobjective green supply chain optimization with a new hybrid memetic algorithm using the Taguchi method," Scientia Iranica, vol. 19, No. 6, 2012, pp. 1876-1886.

[14] K. Shaw, R. Shankar, S. S. Yadav, and L. S. Thakur, "Supplier selection using fuzzy AHP and fuzzy multiobjective linear programming for developing low carbon supply chain", Expert systems with applications, 39(9), 2012, pp.8182-8192.

[15] EPA, "The Lean and Environment Toolkit. U.S. Environmental Protection Agency", http://www.epa.gov/lean/toolkit/index.htm accessed June 26, 2008.

[16] R. Nujoom, A. Mohammed, Q. Wang and N. Bennett, "The multi-objective optimization model for a sustainable manufacturing system design. In Renewable Energy Research and Applications (ICRERA), IEEE International Conference on, 2016 b, pp. 1134-1140.

[17] S. H. Amin, and G. Zhang, "A multi-objective facility location model for closed-loop supply chain network under uncertain demand and return," Applied Mathematical Modelling, vol. 37, No. 6,2013, 416.

[18] Y.L. Lai, and C.L. Hwang, 1992. "Fuzzy mathematical programming," 1st ed., Springer: Berlin, 1992. 